\title{
Natural Environmental Amenities and House Prices - A Hedonic Analysis for Integrated Planning
}

Funlola Famuyiwa ${ }^{1}$

${ }^{1}$ Department of Estate Management, Faculty of Environmental Sciences, University of Lagos, Nigeria

To cite this article: Famuyiwa, F. (2018). Natural Environmental Amenities and House Prices - A Hedonic Analysis for Integrated Planning. Journal of African Real Estate Research, 3(2), pp.44-62. DOI: 10.15641/jarer.v0i0.482.

\begin{abstract}
Environmental valuation techniques have been used to quantify the influences of environmental amenities on house prices. Although this theme has attracted pedagogical attention internationally, a Nigerian perspective relating to effective demand and value systems of natural environmental amenities is lacking significantly. The gap in local market evidence relating to this topic is apparent in comparison to other real estate attributes such as physical infrastructure. In this study, the hedonic pricing model (HPM) is used to evaluate the contributions of environmental amenities to the rental values of detached houses in a submarket in Lagos, Nigeria. This paper, therefore, extends existing body of literature on hedonic studies by contextually assessing the broad category of natural environmental amenities in Lagos. Using a sample of 111 properties, the HPM was used to reveal value inferences of various environmental characteristics on house rents. Results show that 'green environment' as a natural amenity in the housing market studied, produces the highest variation in rental values. This study's significance lies in bringing to light the realities of market demand for natural amenities which, in turn, will help decision makers and public authorities in the strategic planning of the preservation and sustenance of natural amenities.
\end{abstract}

Keywords: Environmental Valuation; Housing Market; Natural Amenities; Physical Infrastructure; Rental Values

\section{Introduction}

There is a growing awareness of the importance of natural environmental amenities for public health, productivity, social and economic development, among others. For example, Littenberg et al. (2015) found that residing in areas with access to the natural environment is associated with better health, which increases the demand for specific housing attributes, such as proximity to green areas, water bodies, and other natural physical 
attractions. Consequently, such features create price premiums in property values that are often omitted or underestimated (Chrysanthou, 2016). Similarly, authors such as Odudu (2003); Adebayo (2006); Famuyiwa and Otegbulu (2012) note that environmental amenities like physical infrastructure also create price premiums in property values - due to functionality, utility and service advantages. The estimation of the worth of environmental amenities is important in urban planning, where decisions on their creation or removal are made (Liebelt, Bartke \& Schwarz, 2017). It is similarly important for policymakers, property valuers, and even real estate investors who engage in large-scale real estate investment decisions. Mahmoudi (2012) explains that such estimates provide support to planners and add quantitative values to public policy debates.

Owens (2014: p.12) defines environmental amenities as "tangible and intangible elements of the environment that contribute to the quality of life". Examples of these amenities are green spaces, and community services. More specifically, the term refers to outdoor public goods and services that give invaluable support to human existence and activities; while also providing recreational, health, psychological, and operational benefits within its coverage area. Contextually, they are sub-divided into 'physical infrastructure' and 'natural environmental amenities'. 'Physical infrastructure' refers to the basic facilities, equipment, and installations needed to provide the utility and services crucial for the growth and functioning of an economy, community, or organisation (Otegbulu, 2010). These services can be provided by government or the private sector. Key examples include: roads, water supply, waste disposal services, and transportation systems. 'Natural environmental amenities' on the other hand, include environmental amenities which owe their existence to natural phenomena. Examples include trees, lakes, rivers, air, green and open spaces. They are aesthetic, ecological, and economical whilst contributing to the sustainability of the ecosystem. Furthermore, they possess physical and psychological effects on human health; are generally environmentally positive embodiments and create positive externalities.

The far-reaching benefits of environmental amenities are particularly crucial for cities like Lagos - a city experiencing rapid and uncontrolled urban growth. Mahmoudi (2012) reports that cities are under pressure to preserve nature and limit suburban sprawl, thus requiring public policy decision makers to have reliable information on the economic value of their open spaces. Chrysanthou (2016: p.4) similarly states that, "by examining the effect of environmental factors on housing prices, the development of urban regions can be promoted through policies and decision-making processes in the markets of residential and urban development".

According to Chaudhry et al. (2013), studies related to the valuation of urban environmental amenities like water bodies and green spaces are very scarce in developing countries. Therefore, this study specifically attempts to draw an analysis of the contributory influences of various environmental attributes (physical infrastructure and natural amenities) on property prices in a developing city such as Lagos. The idea is to examine how the market under examination, values physical infrastructure and natural amenities when placed in the same context. When consumer demand for 
environmental amenities is ascertained and weighed on the same scale with man-made amenities (physical infrastructure), the relative importance of the environmental amenities is brought to light. As such, their individual values and demand indicators can be seen in a 'hierarchical' order. The necessity of this study lies in the fact that the influences of natural (environmental) amenities on house prices have not been adequately addressed in empirical studies in Nigeria when compared with the volume of research on house price influences like physical infrastructure and other housing attributes. Therefore, as a means of linking theory and practice, and because both physical and natural features of an environment are part of a holistic process, they should both be taken into consideration in research.

The generally perceived apathy for natural amenities in Nigeria, in comparison with physical infrastructure, will also be better comprehended in this study as it appears that most Nigerian cities show inadequate consideration or even total neglect for natural features and the development of open spaces. Asikogu and Asikogu (2008) submit that in Nigeria, strategies for implementation have not been adequate to ensure the protection, proper development and maintenance of natural amenities. This has led to total dilapidation, and even destruction of open spaces, green belts and reserves. The high demand for urban land has placed pressure on administrators and resulted in ever-encroaching developments on public parks, gardens and open spaces. Consequently, several neighbourhoods in many urban centres are devoid of green areas, greenery, landscapes and natural amenities. According to Asikogu and Asikogu (2008: p.1) "...in most Nigerian cities, there is a...neglect and even destruction of the open spaces, green belts and reserves...". If decision makers and government - as stakeholders particularly - understand how natural amenities are internalised in property values, the contributory effects can be taxed commensurately so that governments can then make strategic efforts to preserve and sustain these natural amenities. This will help defray the costs of urban development.

This paper is structured into five sections. The first section has introduced the subject matter of the paper. The second section discusses the study's key variables using existing literature. In the third part, the method of study is presented. The fourth section includes the findings and results of the study, while the last section presents concluding remarks.

\section{Previous Studies on the Valuation of Environmental Amenities}

In determining the implicit prices of value inducing attributes in housing markets, several methods have been employed in previous empirical studies, with environmental amenities constituting key variables. Romkaew (2011) reports that researchers have suggested that the characteristics of local neighbourhoods and environmental quality are of great importance in the determination of residential property prices. Wise et al. (2010) observe that the difficulty in house price determination lies in integrating the evaluation of multiple benefits, quantifying benefits that may not be easily monetised, and bringing recognition of these values into infrastructure investment decisions by developers, communities, and agencies. This section reviews how previous studies have addressed the subject matter. 
Simons and Saginor (2006) reviewed several articles that addressed the effect of value influencing environmental amenities on property prices. Regression analyses were used to determine the effect of contamination and amenity variables on property prices. The amenities included beach frontage, water view, parks, golf courses and new housing construction. The study included residential land uses with the hypothesis suggesting that markets can internalise proximity to positive factors. The authors found that the geographic distribution of positive amenities is not as broad as for negative amenities, meaning that most of the amenities were concentrated in some regions and lacking in others. Also, proximity to these features was positive, rather than negative.

Jim and Chen (2007) investigated home buyers' preferences in relation to outdoor environmental attributes and also assessed actual monetary values attributed to environmental externalities - using a Hedonic Pricing Model (HPM). The study area included three housing sub-markets in Guangzhou, China. The variable 'green view' (view of green space) had the most significant positive influence on house prices in the study area. 'Buildings view' (view of buildings) had a negative impact on house prices in all three housing submarkets. Though the authors acknowledged and justified the non-specification of air quality related variables in the survey, not subjecting its significance to empirical analyses within the study area remains untested. This, especially in regions characterised by compact neighbourhoods - given the awareness of the need for outdoor health and recreational opportunities - may not be in ideal consonance with the primary objectives of the study, which mentioned assessing the position of outdoor environmental quality.

Kryvobokov (2007) set out to identify the most important location attributes, which work in market conditions within different countries, and the comparative weights of their influences. A total of 81 models described in 39 sources were analysed. The method of "comparative regression", a form of meta-analysis, was applied in order to extract locational attributes and the weights of their importance. The study found that the lists of statistically significant location variables, which influence market value, are different for various real estate types. It was found that Commercial Business District (CBD) accessibility, the income level of population, prestige, demographic characteristics, accessibility to water (ocean, sea, lake) and road accessibility, were the most important attributes respectively. This was based on the frequency of use, irrespective of the regression form and real estate type. Though the author posited that this list of attributes was not universal - due to the extremely complex socio-economic nature of the market, which will never be formalised entirely because of its subjectivity and intangibility - the focus on a well-developed market may not be extendable to a property market like Lagos.

Henderson and Song (2008) assessed the marginal value of several types of open spaces in a single-family residential market. Using the HPM, variables included: access to different types of open spaces, structural features of the properties, public services, disamenity features, neighbourhood socioeconomic characteristics, and accessibility measures. The findings revealed 
that house prices increase with proximity to certain types of open land uses. It was also discovered that the size of nearby open spaces impacted home prices. Essentially, the value of being adjacent to public open spaces, having more public open spaces within walking distances, and being close to the nearest open space was found to be greater for properties with smaller private yards. Physical infrastructure and other urban facilities were not factored into the model. Additionally, the inclusion of only public spaces and golf courses as environmental attributes might imply model underspecification, as the broad category of such amenities encompasses more than just public spaces and golf courses. Gibbons et al. (2013) also observe that a lot of environmental hedonic studies typically focus on a single or a very limited number of environmental attributes, thereby possibly failing to account for the interplay between multiple environmental amenities and housing preferences.

Gupta, Mythili and Hegde's (2009) study attempted to capture the impact of environmental, structural and location variables on housing prices in Mumbai, India. The revealed preference approach was used to measure the significance of key variables used in a survey covering 578 households. It was found that 'proximity to water body' and 'garden proximity' were the two most significant variables in house price determination. Though the study highlighted proximity to 'railway station' as a variable in the HPM, and was classified as a location attribute, no other public physical infrastructure was considered in the study. Kyrvobokov (2006) suggests that it is the comparative influence of the attributes that is more important than how one or another attribute influences property values.

Chaudhry et al. (2013) used the HPM to study the impact of key environmental attributes like the proximity of an urban lake, having good water quality, parks/gardens, noise attenuation, clean air and traffic, on the market rates of residential plots. The study revealed that air quality showed significant improvement near green spaces. There was, however, no discussion on physical infrastructure valuation and how the market values it in relation to natural environmental amenities.

Khorshiddoust's 2013 study set one major goal. The investigation focused on establishing a correlation between housing choice and environmental characteristics in Tabriz, Iran - where house prices represented the index of payment for the characteristics. The independent variables of this HPM included 'house quality', 'house location', 'proximity to transportation services', 'proximity to business districts', 'green environment' and 'air quality'. The regression results revealed that 'distance from workplace/business districts' possessed the highest coefficient (though negative) among all independent variables. 'Air quality' (natural environmental characteristic) had a coefficient of 0.208 , and 'green area' with a coefficient value of 0.014 , came in much lower ranked than other variables. These implied that 'good air quality' would contribute $20.8 \%$, and the 'availability of green' would contribute $1.4 \%$ to the prices of houses generally. The study concluded that environmental quality in the study area was well capitalised into house prices. While these results are indicative of Iran, they may not be extendable to a city like Lagos given the expected characteristic differences in both markets. Therefore, the independent 
variables in the above regression are somewhat limited to their case study. This case highlights the importance of contextualising a study and its variables.

Melichar et al. (2009), developed an HPM to quantify the influence of structural, accessibility and environmental attributes on the price of housing in Prague. Proximity to the nearest urban forest was an environmental variable and a major focus of the study. Other independent variables of the study included the size of flats (structural variable), distance to the city centre (accessibility variable), the proximity to the nearest tube station (accessibility variable), and distance to the nearest urban forest (environmental variable). Results reveal that a $1 \mathrm{~km}$ increase in the distance from the nearest urban forest reduced house prices by an average of $1.96 \%$. In the light of focusing on the value of an urban forest on house prices, the study also made use of limited independent variables.

Babawale and Johnson (2012) explored the use of an HPM to 'specify' and 'rank' housing attributes that significantly influence the prices of duplexes in a sub-market in Lagos, Nigeria. Independent variables used included: number of bedrooms, number of bathrooms, building size, balcony, construction quality, garage, boys' quarters, swimming pool, plot size, quality of bathroom, distance to work, view of lagoon, availability of schools, availability of shopping centres, availability of recreational facilities, and neighbourhood security. The only natural environmental variable - view of the lagoon, which was included as an independent variable - had a coefficient estimate of 0.0601 (a 6\% contributory influence on property prices) and ranked $8^{\text {th }}$ among the variables tested in the model. The study did not robustly comprise of environmental amenities and as the authors mention and was "limited by the information typically found in the area under reference" (Babawale \& Johnson, 2012: p.4).

Famuyiwa and Babawale (2014) examined the relationship and pricing effects of physical infrastructure on house rentals using the HPM on a housing market in Lagos Nigeria. The results showed the contributory influences of physical infrastructure to house prices in the study area. The study however explicitly concentrated on physical (human-made) infrastructure.

One thing common to all the studies reviewed is the impact that environmental amenities have on property prices. This present study contributes to knowledge by demonstrating effective demand levels for natural amenities and physical infrastructure within a middle-class housing submarket in Lagos, Nigeria.

\section{Study Area and Research Methods}

This study covered Yaba Local Council Development Area (LCDA) of Lagos State which is one of the two LCDAs of Lagos Mainland Local Government Area of Lagos State, Nigeria. It is one of the 57 LCDAs of 20 Local governments in Lagos State. Lagos itself is one of the 36 states that make up the Federal Republic of Nigeria. Though Lagos ceased to be the administrative and political capital of Nigeria in 1991, it remains the centre 
of commerce and economic development with the highest population density in the country (Lagos State Government, 2017). The study area is located within the geographical coordinates $6^{\circ} 29^{\prime} 23^{\prime \prime}$ North, $3^{\circ} 23^{\prime} 1^{\prime \prime}$ East and remains one of the few areas in the metropolis that evinces the colonial heritage of Lagos.

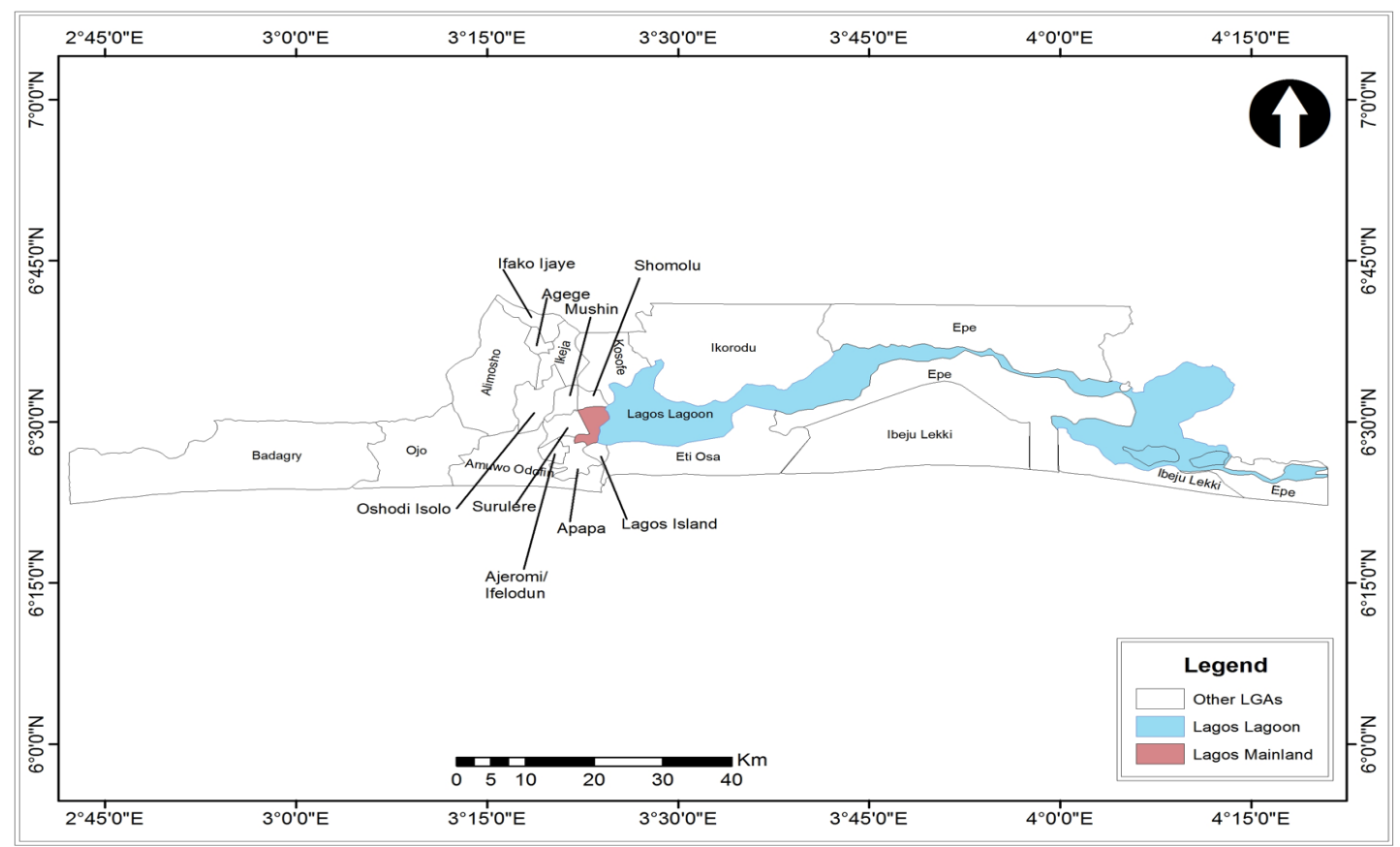

Figure 1: Map of Lagos State, Nigeria Showing the 20 Local Government Areas

Yaba is characterised by mixed land uses and people of mixed socioeconomic backgrounds. It is one of the commercial nerve centres of the Lagos metropolis, though some portions of it (Makoko and Iwaya areas) mirror rural features. These areas, due to their slum characteristics, were not covered in this study in order to avoid possible bias in the aggregated results. Such areas characteristically have little or no amenities such that the variables employed would have no significance or relevance in the results. The particular use of Yaba area for study was due to its environmental characteristics. It is one of the few locations in Lagos possessing a fair amount of greenery such as trees - conceivably influenced by its colonial heritage. 


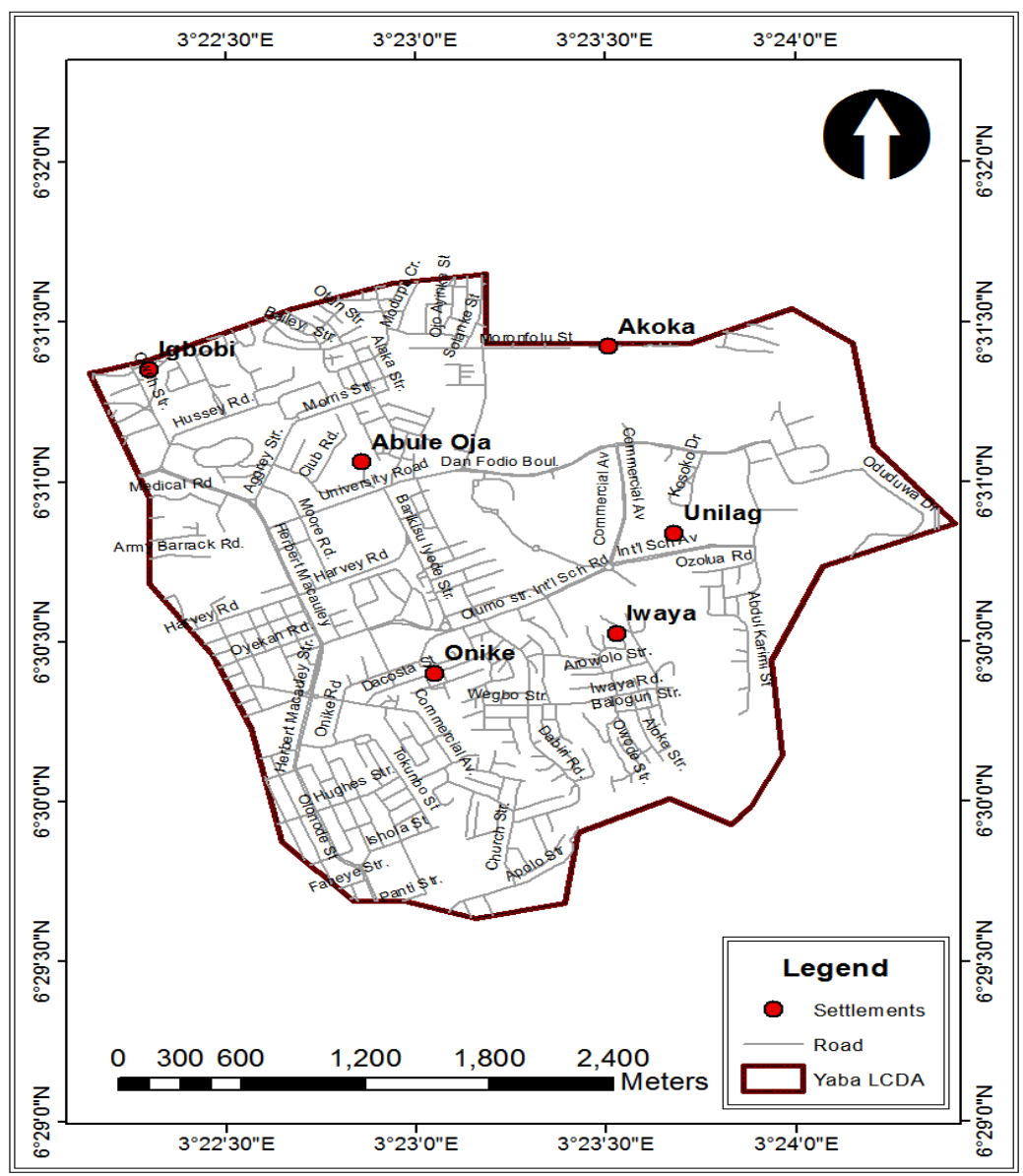

Figure 2: Study Area - Yaba Local Council Development Area, Lagos, Nigeria

In Lagos, official data of housing transactions and characteristics are generally not available. Though the Lands Registry holds information pertaining to various land plots, such information may not be readily available for 'public consumption'. Consequently, the main research instrument used was the structured questionnaire. The sample selection entailed the use of a two-stage sampling technique. In this sampling technique, first, the researcher selects a few groups or clusters (which are usually geographically defined and randomly chosen), and then from each cluster, the researcher selects the individual sampling units by random sampling to obtain a two-stage cluster sample (Valliant et al., 2013). Hence, Yaba LCDA (the study area) was fragmented into smaller non-overlapping areas (streets). In the second stage, four questionnaires were administered on each street by a random selection of four detached buildings on each street. A total number of 45 streets had been identified in the study area. 180 questionnaires were therefore administered. The questionnaires were handed to household heads (or other property occupants deemed capable of responding to the questions, where household heads were unavailable).

The completed questionnaires were cross-checked with physical site assessments upon collection for objectivity in variable measurements especially 'plot size'. However, this check was not possible in all cases, as not all respondents gave the field assistants such access. This reduced the 
usable questionnaires. Therefore, from 135 questionnaires retrieved, only 111 were found suitable for analyses. The dependent variable 'rental value' was not included in the questionnaires. This information was sought from qualified estate valuation practitioners within the operative jurisdiction. The focus on detached buildings was borne out of its neglect in the literature. More importantly, detached properties are among the highest priced class of residential properties in most markets with occupiers who are more likely to be particular about the various features and characteristics of their properties. Hence, developers in the study area would be able to meet buyers' tastes and preferences easily.

The data gathered was analysed using both descriptive and inferential statistics. The HPM was used to reveal value inferences of various environmental characteristics used in the study. This model involves the isolation of the underlying price paid for each individual characteristic of the property using regression techniques (Chau \& $\mathrm{Ng}, 1998$ ). In Famuyiwa and Babawale (2014), the pricing analysis is based on transaction information and related measures of theoretical variables that enable empirical examination of house prices. This is due to its clearly defined objective approach depicted in the analysis of effective demand as opposed to perceptions of demand. For these reasons, it has been a preferred environmental valuation technique. Franz (2007), explains that the HPM has become the standard methodology for examining price determinants in real estate research. The use of rental values in hedonic pricing has been demonstrated in existing studies, for example in Hoesli et al. (1997) and Weinberger (2001). Weinberger (2001) submits that rental rates are more abundant and dynamic, thus more sensitive to changes in the market, allowing for more robust models. In the Lagos property market, this is particularly true. The Lagos property market is known to have a more active property rental market than its capital/sales market as evinced in property market transactions.

The variables for the study were drawn from similar studies (Babawale \& Johnson, 2012; Famuyiwa \& Babawale, 2014) and then modified to suit the specific circumstances. This "modification" was also attained through a pilot study. During this initial trial run, questionnaires were administered to a total of 14 participants (10\% of the projected sample size). The pilot study showed that the scales used in the questionnaires were adequate. Grammatical instructions were simplified and made easily understandable in the main study (as lessons learnt from the pilot). Additionally, questions were shortened as respondents were found to get frustrated with long questions. The pilot was also used to identify variables relevant to net rental values of houses in the study area. As a general rule, it is better to overspecify the HPM than to under-specify it, otherwise 'omitted variable bias' could occur (Johnson-Gardner, 2007). This happens when key variables that should be included in the HPM are not included which leads to results that over-express the importance of an included independent variable's explanatory power.

A quintessential estimated equation for an HPM, in a semi-logarithmic (loglinear) form, may be specified in the following form: 
$\mathbf{P}_{\mathbf{n}}=\beta_{0}+\beta_{\mathrm{s}} \mathrm{S}_{\mathrm{ij}}+\beta_{\mathrm{l}} \mathrm{L}_{\mathrm{ij}}+\beta_{\mathrm{n}} \mathrm{N}_{\mathrm{ij}}+\mathrm{Z}_{\mathrm{ij}}$

Where:

$\mathbf{P}_{\mathbf{n}}=$ Annual rental (value) in Naira of properties under study.

$\boldsymbol{\beta}_{0}=$ The constant.

$\boldsymbol{\beta}=\quad$ Vector of the natural log of explanatory structural, locational and neighbourhood characteristics of the property.

$\mathbf{S}_{\mathrm{ij}}=$ The regression coefficient representing structural effects on housing rental value.

$\mathbf{L}_{\mathbf{i j}}=$ The regression coefficient representing location effects on housing rental value.

$\mathbf{N}_{\mathbf{i j}}=$ The regression coefficient representing neighbourhood effects on housing rental value.

$\mathbf{z}_{\mathbf{i j}}=$ The random error and stochastic disturbance term (for unobserved parameters) that is expected to take the form of a normal distribution with a mean of zero and a variance of $\boldsymbol{\alpha}^{2}$.

The 'constant' represents the starting point of any examination of results produced by HPM, and it is the base to which other variables are added (Dunse \& Jones, 1998). The random error represents non-observed factors omitted from the analyses. Table 1 below describes the variables used, their acronyms and measurements.

Table 1: Definition of Regression Variables

\begin{tabular}{|c|c|c|}
\hline Variable Definition & Acronym & Measurement \\
\hline Net Rental Value & RENT & $\begin{array}{l}\text { Measurement in Nigerian Currency } \\
(\mathrm{N}) \text { - Naira }\end{array}$ \\
\hline Structural Quality of Property & STRQUAL & Good $=1 ;$ Poor $=0$ \\
\hline State of Repair of Property & REPAIR & Good $=1 ;$ Poor $=0$ \\
\hline Living room & LIVIN & Numerical value \\
\hline Bedroom & BED & Numerical value \\
\hline Bathroom & BATH & Numerical value \\
\hline Store & STORE & Available $=1 ;$ Not available $=0$ \\
\hline Balcony & BCNY & Available $=1 ;$ Not available $=0$ \\
\hline Plot Size & PLOT & In Square metres \\
\hline Natural Lighting & NTLIGHT & Good $=1 ;$ Poor $=0$ \\
\hline $\begin{array}{l}\text { Distance to Closest Central Business } \\
\text { District }\end{array}$ & DISCBD & $\begin{array}{l}\text { "1" if within } 15 \text { minutes walking } \\
\text { distance, "0" if otherwise }\end{array}$ \\
\hline Distance to Recreation Centres & DISRECR & $\begin{array}{l}\text { "1" if within } 15 \text { minutes walking } \\
\text { distance, "0" if otherwise }\end{array}$ \\
\hline Neighbourhood Security & SECRTY & Good $=1 ;$ Poor $=0$ \\
\hline Neighbourhood Serenity & SERENE & Good $=1 ;$ Poor $=0$ \\
\hline Condition of Road Surface & ROAD & Good $=1 ;$ Poor $=0$ \\
\hline Government Water Supply & WATER & Good $=1 ;$ Poor $=0$ \\
\hline Government Waste Disposal Services & WASTE & Good $=1 ;$ Poor $=0$ \\
\hline Street Lightings & SRTLIGHT & Good $=1 ;$ Poor $=0$ \\
\hline Nature of Drainage & DRAIN & Good $=1 ;$ Poor $=0$ \\
\hline $\begin{array}{l}\text { Green Environment in Neighbourhood } \\
\text { (e.g. trees, flowers) }\end{array}$ & GREEN & Good $=1 ;$ Poor $=0$ \\
\hline Private Garden Space & GARDEN & Good $=1 ;$ Poor $=0$ \\
\hline
\end{tabular}




\begin{tabular}{|l|l|l|}
\hline Wind Quality in Building (Ventilation) & WINDQUA & Good $=1$; Poor $=0$ \\
\hline Landscape of Neighbourhood & LSCAPE & Good $=1$; Poor $=0$ \\
\hline View of Navigable water body & VIEWWAT & Good $=1$; Poor $=0$ \\
\hline
\end{tabular}

\section{Findings and Discussion}

In Table 2 the descriptive statistics of the sampled residential properties in the study area are displayed. Apart from 'net rental value', 'living room', 'bedroom', 'bathroom', and 'plot size', all other variables were estimated using binary measurements. The average net rental value (dependent variable) of detached buildings in the area is N1,604,879 while maximum and minimum values are $\mathrm{N} 3,600,000$ and $\mathrm{N} 1,450,000$ respectively.

Table 2: Descriptive Statistics of Regression Variables

\begin{tabular}{|c|c|c|c|c|}
\hline & MINIMUM & MAXIMUM & STD & MEAN \\
\hline RENT & $1,450,000$ & 3600000 & 238030 & $1,604,879$ \\
\hline STRQUAL & .00 & 1.00 & .24085 & .92333 \\
\hline REPAIR & .00 & 1.00 & .32048 & .81775 \\
\hline LIVIN & 1.00 & 2.00 & .04822 & 1.61098 \\
\hline BED & 3.00 & 5.00 & .28616 & 4.00723 \\
\hline BATH & 2.00 & 5.00 & .48250 & 3.59881 \\
\hline STORE & .00 & 1.00 & .49983 & .555641 \\
\hline BCNY & .00 & 1.00 & .22081 & .880378 \\
\hline PLOT & 592.73 & $1,406.91$ & 193.68204 & 736.75291 \\
\hline NTLIGHT & .00 & 1.00 & .00985 & .68080 \\
\hline DISCBD & .00 & 1.00 & .39225 & .61046 \\
\hline DISRECR & .00 & 1.00 & .40391 & .42907 \\
\hline SECRTY & .00 & 1.00 & .36119 & .64816 \\
\hline SERENE & .00 & 1.00 & .00839 & .32832 \\
\hline ROAD & .00 & 1.00 & .40071 & .63784 \\
\hline WATER & .00 & 1.00 & .23641 & .60120 \\
\hline WASTE & .00 & 1.00 & .21093 & .76059 \\
\hline SRTLIGHT & .00 & 1.00 & .38658 & .32199 \\
\hline DRAIN & .00 & 1.00 & .47550 & .66493 \\
\hline GREEN & .00 & 1.00 & 10993 & .78036 \\
\hline GARDEN & .00 & 1.00 & .09001 & .29732 \\
\hline WINDQUA & .00 & 1.00 & .33029 & .62435 \\
\hline LSCAPE & .00 & 1.00 & .30723 & .57446 \\
\hline VIEWWAT & .00 & 1.00 & .00033 & .00778 \\
\hline
\end{tabular}


From Table 2, it can be seen that the number of bedrooms ranges from 3 to 5 with a standard deviation of 0.28616 , implying a low dispersion around a mean of 4.00723. The mean for 'natural lighting' is 0.68080. Sixty-five per cent $(65 \%)$ have 'good neighbourhood security', while the conditions of road surfaces of about $64 \%$ of these properties are good. Only about $60 \%$ of the properties have access to public pipe-borne water, and about $76 \%$ dispose of their domestic waste using government waste disposal services. Only about $32 \%$ of the properties have streetlights around their premises. Other variables can be interpreted from the mean values and standard deviations in the table accordingly.

\subsection{Model Evaluation}

There is little guidance from economic theory about the proper functional relationship between house price and its attributes (Selim, 2008). The estimation and selection of appropriate HPM have therefore been of significant concern. Widely used functional forms include the 'linear' form, the 'semi-logarithmic' form (log-linear) and the 'log-log'. Consequently, this study analysed field data using these three models. The three models utilised, depict the preponderance of these methods in similar studies. All three models used, (only the log-linear model shown) yielded significant coefficients and good model statistics. The log-linear model performed most satisfactorily, in terms of its ability to predict property value influences in the study area as indicated by its $\mathrm{R}^{2}$ and Adjusted $\mathrm{R}^{2}$ statistics of 0.790123 and 0.723652 respectively. An $\mathrm{R}^{2}$ of 0.790123 infers that about $79 \%$ of variance in rental values is accounted for by the joint influence of all explanatory variables. The adjusted $\mathrm{R}^{2}$ explains only the variation accounted for by the significant variables. The individual relationship of each of the attributes to value is shown in the second column of Table 3 (tagged 'coefficients'). Babawale and Johnson (2012), remark that high values of $\mathrm{R}^{2}$ do not necessarily ensure the accuracy of models. Hence, tests were carried out to check for 'multicollinearity' and 'heteroskedasticity'.

Multicollinearity is a statistical phenomenon when two or more independent variables in a multiple regression model are highly correlated (Xiao, 2017). This is undesirable in statistics as the estimate of one variable's impact on the dependent variable while controlling for the others tends to be less precise. 'Heteroskedasticity' on the other hand refers to a statistical phenomenon where the variance of the dependent variable varies across the data. Babawale and Johnson (2010) imply that the variance of the errors of the data increases or decreases. The White's test and Variance Inflation Factor (VIF) statistics were used to check for heteroskedasticity and multicollinearity respectively. In the White's Test, the F-statistic of 1.682110, the Obs*R-squared (51.481659), and p-values indicate constancy of the random error. The P-value of 0.043974 is the probability that random error is not heteroskedastic (not higher than 5 per cent). Table 5 shows a maximum VIF value of 2.99256, which is low, desirable and indicative of the absence of multicollinearity in the model. If the VIF of a variable exceeds 10, that variable is said to be highly collinear and will pose a problem in the analysis (Hair et al., 2006 cited in Hill \& Throshani, 2009). All these imply that the data fits well into the regression line and the model is adequate in explaining changes in rental values for the category of 
property in the study area. Consequently, the model appears adequate for predicting rental values of detached buildings in the study area.

Table 3: Regression Results

\begin{tabular}{llc}
\hline & \multicolumn{2}{c}{ Log-linear Model } \\
\hline Variables & Coefficients & T- statistics \\
STRQUAL & .191025 & 1.733654 \\
REPAIR & .081544 & 1.380998 \\
LIVIN & .084432 & 3.994811 \\
BED & .072237 & 3.410468 \\
BATH & .061126 & 4.736524 \\
STORE & .090283 & 3.028461 \\
BCNY & .152038 & 3.842652 \\
PLOT & .008826 & 3.947261 \\
NTLIGHT & .009435 & 6.884632 \\
DISCBD & .280001 & 1.920375 \\
SECRTY & .000983 & 1.677463 \\
ROAD & .120567 & 1.814028 \\
WATER & .097635 & 2.376251 \\
WASTE & -.039012 & -3.429712 \\
SRTLIGHT & .050754 & 1.092836 \\
DRAIN & .009127 & 2.348283 \\
GREEN & .170362 & 2.736555 \\
WINDQUA & .011275 & 1.983463 \\
LSCAPE & .093552 & 5.012254 \\
VIEWWAT & .034900 & 4.773652 \\
Constant & 14.994821 & 37.839204 \\
R & .790123 & \\
Adjusted R ${ }^{2}$ & .723652 & \\
F-statistic & 19.336092 & \\
Prob & .050000 & \\
Source: Field Study, 2016 & & \\
STH & & \\
\hline
\end{tabular}

Table 4: White's Test

\begin{tabular}{llll}
\hline F-Statistic & 1.682110 & Probability & 0.043974 \\
Obs*R-squared & 51.481659 & Probability & 0.408321 \\
\hline
\end{tabular}

Table 5: Collinearity Statistics

\begin{tabular}{ll}
\hline & VIF \\
\hline STRQUAL & 1.73635 \\
REPAIR & 2.00483 \\
LIVIN & 1.04877 \\
BED & 1.94763 \\
BATH & 1.04987 \\
STORE & 1.77465 \\
BCNY & 2.53684 \\
PLOT & 2.99256 \\
NTLIGHT & 1.02736 \\
\hline
\end{tabular}




\begin{tabular}{ll}
\hline DISCBD & 1.99715 \\
SECRTY & 1.37541 \\
ROAD & 2.55301 \\
WATER & 1.37599 \\
WASTE & 1.90548 \\
SRTLIGHT & 2.40918 \\
DRAIN & 1.28285 \\
GREEN & 2.48635 \\
WINDQUA & 2.34975 \\
LSCAPE & 1.11906 \\
VIEWWAT & 1.65421 \\
\hline
\end{tabular}

\subsection{Interpretation of Independent Variables}

The results from the log-linear model as seen in Table 3 indicate real estate attributes (variables) that predict rental values as described in Table 1. Variables with negative coefficients imply an inverse relationship with rental values and vice versa. The coefficients in the log-linear model are interpreted as variations in rental values when there is a change (per measurement unit) in a given variable. Accordingly, 'good structural quality' contributes $19 \%$ to rental values. For every additional living room, bedroom and bathroom, rental values increase by $8.4 \%, 7.2 \%$ and $6 \%$ respectively. Other independent variables in the table can be interpreted in the same way. For variables categorised as 'natural environmental attributes', the study suggests that 'green environment in neighbourhood' accounts for $17 \%$ of variation in rental values, while 'good landscape' contributes up to $9.3 \%$ to rental values.

In terms of physical infrastructure; 'government waste disposal services' possesses an adverse effect on rental values implying that houses serviced by government waste management agencies will likely experience a $3.9 \%$ decline in rental value, thereby contradicting existing theory of the positive effect which infrastructure has on property values. Further investigation into this suggests that this is because the erratic and unreliable state of government services has given rise to aesthetic issues with waste littering the streets due to delays in waste collection. This thereby constitutes a negative externality and impacts negatively on rental values.

Although the distance to Central Business District (CBD) possesses the highest coefficient value (confirming location as one of the most significant factors to property value), its significance level is low. Natural environmental amenities performed almost at par with human-made amenities from the coefficient values. However, the strongest unique contribution (asides distance to CBD) explaining rental values is 'green environment in neighbourhood' with the highest coefficient value of $0.170362(17 \%)$. This implies that this particular variable is highly valued. Natural environmental amenities like 'view of navigable water body', account for only about $3.4 \%$ of variation in rental values in the study area. Some independent variables which are excluded in the regression table are due to their insignificance, e.g. 'distance to recreational centres (DISRECR)'. The variables 'plot size (PLOT)' and 'private garden space (GARDEN)' were found to highly correlate, thus introducing the problem of 
multicollinearity. This was surmounted by eliminating the independent variable 'GARDEN'; from the model. The resultant regression equation derived from the (standardised) coefficients is as follows:

\section{Equation 1: Regression Equation of Log-Linear Model}

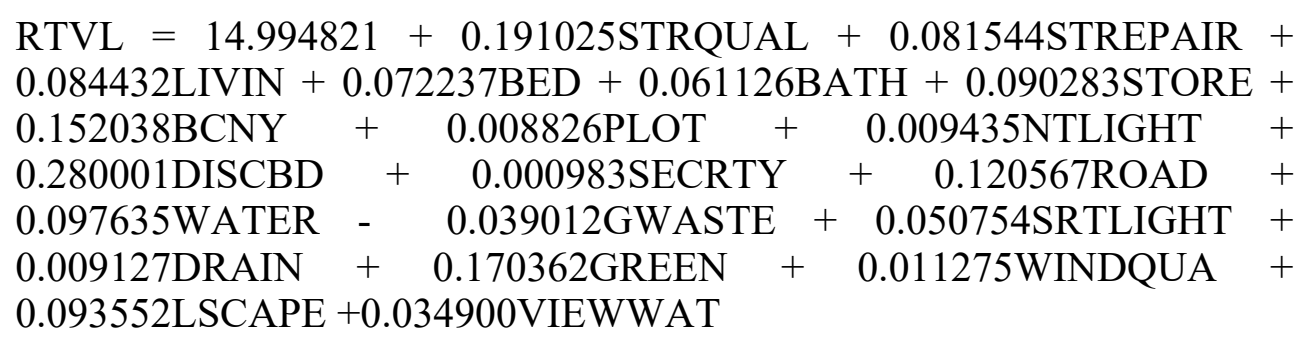

The results of the study appear to be in consonance with other emerging housing markets, like China. This is in reference to Jim and Chen's (2007) study which found 'green view' to be the most significant influence on the housing market in Guangzhou. In this study, however, 'location' was found to be a more important contributory factor to house rental prices than environmental features. However, among environmental features, the natural environment (green environment) was found more important than any physical infrastructure. Similarities were also observed in results with other studies, highlighting the generic nature of environmental attributes to property values across study areas. For example, Khorshiddoust's (2013) study, found environmental characteristics possessing significant coefficients, where 'Green Area' with a coefficient value of 0.014 was found to be significant. Perhaps this could be due to the fact that Khorshiddoust's study also covered a developing country. The findings of this study also confirm the statement in Melichar et al. (2009: p.2) that "with few exceptions... Studies find that homes adjacent to nature and open spaces are typically valued at about 8 to 20 per cent more than comparable properties".

\section{Conclusion}

As previous hedonic pricing studies have shown, the effects of environmental amenities on the price of housing are measurable and significant. This study aimed to evaluate the implicit prices of both humanmade and natural environmental amenities in rental values of detached residential houses within Yaba LCDA in Lagos State, Nigeria. It was carried out using the hedonic regression model on 111 rental observations. The study employed primary data including information on property rentals and attributes of detached houses. The aggregated influence of various housing attributes was analysed using the log-linear model. The model accounted for $79 \%$ of variations in rentals of detached houses, which is good as it is greater than the $70 \%$ threshold value posited by Pallant (2005).

The findings suggest comparable influences of natural environmental amenities with human-made amenities in terms of coefficient values. This provides evidence and confirmation of the almost equivalent importance of environmental amenities, whether natural or human-made in the sub-market of detached properties in Yaba LCDA. In spite of the generally perceived 
apathy for natural amenities in Nigeria as featured in the writings of previous authors such as Asikogu and Asikogu (2008), the effective demand for natural amenities is comparable to that of physical infrastructure in the study area. This implies that housing consumers value, and are willing to pay for, natural amenities as well as physical infrastructure in the study area.

The evaluation of natural environmental amenities and human-made amenities should, therefore, be equally considered in neighbourhood and town planning schemes, especially where cost considerations are decisive factors. The demand for housing necessarily embodies the demand for places, access to public and private services, physical infrastructure and natural environmental amenities. Therefore, to achieve sustainable environments, those involved in regional planning processes must consider the interaction between human-made environmental amenities and the natural environment, as both are very crucial to the well-being of inhabitants, and sustainability of the built environment.

In Lagos today, the rapid pace of 'creating land' for new buildings has left several parts of the city without green spaces, or natural amenities. According to Mensah (2014), in a study of some selected African cities including Lagos, rapid urbanisation is attributed to the conversion of many reserved green spaces for development to meet the soaring urban population. The colonial fabric of the study area; characterised by wellplanned, open spaces, green fields, trees, and other natural features, is fast disintegrating as observed in the field study - even though they still possess price premiums as evidenced in rental values. Additionally, the state of physical infrastructure is a major source of concern for both stakeholders and decision-makers. Therefore, the way and manner in which they are deployed are crucial in the development process, due to their externalities and monopolistic features.

The main recommendation arising from this study is hinged on the fact that environmental amenities (both human-made and natural) create price premiums, and therefore should be well developed and commensurately taxed as indicated in their contributory effects to property values/effective demand. This supports a holistic approach to urban planning and development. The benefits on health, productivity and economic development cannot be overemphasised.

In conclusion, the influences of both human-made and natural environmental amenities on property prices should be given increased attention in empirical discourse. This study can be extended to cover consumer preference of environmental amenities, cost-benefit analyses, as well as the willingness-to-pay for environmental amenities - especially in developing markets.

\section{References}

Adebayo, M.A. (2006). The State of Urban Infrastructure and its Effects on Property Values in Lagos, Nigeria. Journal of Land Use and Development Studies, 2(1), pp.1-10. 
Asika, N. (1991). Research Methodology in the Behavioural Sciences. Lagos: Longman Nigeria Plc.

Asikogu, L.U. \& Asikogu, U.A. (2008). The Imperative of Open Spaces and Recreation Parks in the Master Plan of a City. Journal of Research in National Development Volume, 6(2).

Babawale, G.K. \& Johnson, O. (2012). The Specification of Hedonic Indexes for Duplexes in Lekki Peninsular Area of Lagos Metropolis. Elixir Social Science Journal, 45, pp.7689-7698.

Chau, K.W. \& Ng, F.F. (1998). The Effects of Improvement in Public Transportation Capacity on Residential Price Gradient in HongKong. Journal of Property Valuation and Investment, 16(4), pp.397410.

Chaudhry, P., Sharma, M.P., Singh, G. \& Bansal, A. (2013). Valuation of Urban Environmental Amenities in Developing Countries: A Case Study from Chandigarh, India. Global Journal of Science Frontier Research Environment \& Earth Science, (13)2, pp.1-12.

Chrysanthou, A. (2016). The Effect of Environmental Amenities on House Prices - The Inner City of London. Research Proposal. Erasmus University Rotterdam. [Online]. Available at:

https://thesis.eur.nl/pub/34028/BA-scriptie-Chrysanthou-A.pdf (Accessed $14^{\text {th }}$ July 2018).

Des Rosiers, F., Bolduc, A. \& Theriault, M. (1999). Environment and Value: Does Drinking Water Quality Affect House Prices? Journal of Property Investment \& Finance, 17(5), pp.444-463.

Dunse, N. \& Jones, C. (1998). A Hedonic Price Model of Office Rents. Journal of Property Valuation and Investment, 16(3), pp.297-312.

Famuyiwa, F. \& Babawale, G.K. (2014). Hedonic Values of Physical Infrastructure in House Rentals. Journal of Facilities Management, 12(3), pp.211-230.

Famuyiwa, F. \& Otegbulu A.C. (2012). Public Water Infrastructure in Property Prices: An Environmental Valuation Approach. Elixir Infrastructure Mgmt., 51, pp.11034-11038.

Gardner, J. (2007). An Assessment of the Marginal Impact of Urban Amenities on Residential Pricing. Working paper for Metro. 319 SW Washington, Suite 1020 Portland, OR 97204.

Ge, J.E. \& Du, Y. (2007). Main Variables Influencing Residential Property Values Using the Entropy Method - The Case of Auckland. Paper Presented at the Proceedings of the 5th International Structural Engineering and Construction Conference. Shunan, Japan. [Online]. Available at: https://www.asres2007.umac.mo/papers/041\%20\%20PAPER.pdf (Accessed $5^{\text {th }}$ March 2017).

Gupta, V., Mythili, G. \& Hedge. D.S. (2009). Deriving Implicit Prices for Urban Environmental Amenities from Mumbai Housing Prices - A Revealed Preference Approach. Paper presented at the First International Conference on Landscape Economics, at the University of Natural resources and Applied Life Sciences. July 2-4, Vienna.

Hao, J. \&Wang, L. (2012). Improving Urban Air Quality in China: Beijing Case Study. Journal of the Air \& Waste Management Association, 55(9), pp.1298-1305. DOI: 10.1080/10473289.2005.10464726 
Henderson, K.K. \& Song, Y. (2008). Can Nearby Open Spaces Substitute for the Size of a Property Owner's Private Yard? International Journal of Housing Markets and Analysis, 1(2), pp.147 - 165.

Hoesli, M., Thion, B. \& Watkins, C. (1997). A Hedonic Investigation of the Rental Value of Apartments in Central Bordeaux. Journal of

Property Research, 14(1), pp.15-26.

DOI:10.1080/095999197368735

International Valuation Standards Committee. (2011). Australian And New Zealand Valuation and Property Standards. [Online]. Available at: www.propertystandards.propertyinstitute-wa.com/documents/IVSC3 000.pdf (Accessed 24 $4^{\text {th }}$ July 2013).

Jim, C.Y. \& Chen, W.Y. (2007). Consumption Preferences and Environmental Externalities: A Hedonic Analysis of the Housing Market in Guangzhou. Elsevier Journal Geoforum, 38, pp.414-431.

Khorshiddoust, A.M. (2013). Hedonic Prices and Environmental Classification of Economic Values of Selected Areas of Tabriz. International Journal of Economics and Finance Studies, 5(2), pp.108-121.

Kryvobokov, M. (2006). What location attributes are the most important for market value? Extraction of attributes from regression models. Property Management, 3(25), pp.257-286.

Lagos State Government. (2017). About Lagos. [Online]. Available at: https://lagosstate.gov.ng/about-lagos/ (Accessed $8^{\text {th }}$ April 2018).

Land Policy Institute. (2007). Economic Valuation of Natural Resource Amenities. A Hedonic Analysis of Hillsdale And Oakland Counties. (Report \#3 Series on Economic Impact and Valuation Studies in Natural Resources and Conservation). Land Policy Institute, Michigan State University, USA.

Liebelt, V., Bartke, S. \& Schwarz, N. (2017). Hedonic Pricing Analysis of the Influence of Urban Green Spaces onto Residential Prices: The Case of Leipzig, Germany. European Planning Studies, 26(1), pp.133-157. DOI: 10.1080/09654313.2017.1376314

Littenberg, B., Bonnell, L.N., LeBruin, A.S., Lubetkin, D.A., Troy, A.R. \& Zia, A. (2015). The Relationship Between Access to Natural Environmental Amenities and Obesity. Cureus, 7(11), pp.377-390. DOI: $10.7759 /$ cureus.377

Mahmoudi, P. (2012). Environmental Amenities and Local Development in Australia: Spatial Hedonic Pricing and Regional Economic Models. Doctoral Dissertation. University of Adelaide. [Online]. Available at: https://digital.library.adelaide.edu.au/dspace/handle/2440/72858 (Accessed $3^{\text {rd }}$ August 2017).

Melichar, J., Vojacek, O., Rieger, P. \& Jedlicka, K. (2009). Measuring the Value of Urban Forests Using the Hedonic Price Approach. Czech Regional Studies, 2, pp.13-20.

Mensah, C.A. (2014). Destruction of Urban Green Spaces: A Problem Beyond Urbanisation in Kumasi City (Ghana). American Journal of Environmental Protection, 3(1), pp.1-9.

DOI:10.11648/j.ajep.20140301.11

Odudu, C. (2003). Significance of Infrastructure in Determining Land and Rental Values in an Urban Area-The Case of Lagos Metropolis. Land Management and Property Tax Reform in Nigeria- 
Proceedings of a National Workshop organised by the Department of Estate Management, University of Lagos, Nigeria.

Organisation for Economic Co-operation and Development. (1994). The Contribution of Amenities to Rural Development. Paris: OECD

Otegbulu A. (2010). An Assessment of User-Demand Preference of Urban Infrastructure in Lagos Metropolis Using the Contingent Valuation Model. Unpublished Doctoral Dissertation. Department of Geography and Meteorology Enugu State University.

Owens, C. (2014). Envisioning Change: Examining Environmental Amenities and Disamenities in the Southern Sector of Dallas, Texas. Master's Dissertation. Nicholas School of the Environment, Duke University. [Online]. Available at:

https://dukespace.lib.duke.edu/dspace/bitstream/handle/10161/8496/ Christa\%200wens MP Final.pdf? sequence $=1 \&$ is Allowed $=y$ (Accessed 22 ${ }^{\text {nd }}$ December 2017).

Pallant, J. (2005). SPSS Survival Manual: A Step by Step Guide to Data Analysis Using SPSS. Allen \& Unwin Crow's Nest NSW 206, Australia.

Romkaew N. (2011). Evaluating the Effects of Infrastructure Effects on Residential Property. Masters Dissertation. RMIT University Melbourne Australia. [Online]. Available at:

http://www.prres.net/papers/Romkaew_EVALUATING_THE_CON TRIBUTION_OF_INFRASTRUCTURE_EFFECTS.pdf

Rosen, S. (1974). Hedonic Prices and Implicit Markets: Product Differentiation in Pure Competition. Journal of Political Economics, 82(1), pp.34-55.

Selim, S. (2008). Determinants of House Prices in Turkey: A Hedonic Regression Model. Doğuş Üniversitesi Dergisi, 9(1), pp.6576.

Valliant, R., Dever, J. A. \& Kreuter, F. (2013). Practical Tools for Designing and Weighting Survey Samples. Springer, Berlin. MR3088726

Weinberger, R. (2001). Commercial Property Values and Proximity to Light Rail: A Hedonic Price Application. Doctoral Dissertation. University of California Berkeley. [Online]. Available at:

http://uctc.berkeley.edu/research/diss100.pdf (Accessed 16 ${ }^{\text {th }}$ March 2017).

Wise, S., Braden, J., Ghalayini, D., Grant, J., Kloss, C., MacMullan, E. \& $\mathrm{Yu}, \mathrm{C}$. (2010). Integrating Valuation Methods to Recognise Green Infrastructure's Multiple Benefits. [Online]. Available at: http://www.cnt.org/repository/CNT-LID-paper.pdf (Accessed 31 August 2017).

Xiao, Y. (2017). Urban Morphology and Housing Market. Springer Singapore. DOI 10.1007/978-981-10-2762-8_2 